\title{
Grainyhead-Like Protein 2 Homolog
}

National Cancer Institute

\section{Source}

National Cancer Institute. Grainyhead-Like Protein 2 Homolog. NCI Thesaurus. Code C162374.

Grainyhead-like protein 2 homolog ( $625 \mathrm{aa}, \sim 71 \mathrm{kDa}$ ) is encoded by the human GRHL2 gene. This protein plays a role in neurulation and the morphogenesis and maintenance of epithelially derived tissues. 